\title{
Perianal Fistula With and Without Abscess: Assessment of Fistula Activity Using Diffusion-Weighted Magnetic Resonance Imaging
}

\author{
Selim Bakan," Deniz Cebi Olgun, Sedat Giray Kandemirli, ${ }^{1}$ Onur Tutar, ${ }^{1}$ Cesur Samanci, \\ Suleyman Dikici, Osman Simsek, ${ }^{2}$ Babak Rafiee, ${ }^{1}$ Ibrahim Adaletli, ${ }^{1}$ and Ismail Mihmanli ${ }^{1}$ \\ ${ }^{1}$ Department of Radiology, Cerrahpasa Medical Faculty, Istanbul University, Istanbul, Turkey \\ ${ }^{2}$ Department of General Surgery, Cerrahpasa Medical Faculty, Istanbul University, Istanbul, Turkey \\ ${ }^{*}$ Corresponding author: Selim Bakan, Department of Radiology, Cerrahpasa Medical Faculty, Istanbul University, Istanbul, Turkey. Tel: +90-2124143167, Fax: +90-2124143167, \\ E-mail: dr.selim79@gmail.com
}

Received 2015 April 8; Revised 2015 June 9; Accepted 2015 July 12.

\begin{abstract}
Background: Magnetic resonance imaging (MRI) is highly accurate for the depiction of both the primary tract of fistula and abscesses, in patients with perianal disease. In addition, MRI can be used to evaluate the activity of fistulas, which is a significant factor for determining the therapeutic strategy.

Objectives: This study aimed to determine the usefulness of diffusion-weighted (DW)MRI for assessing activity and visibility of perianal fistula.

Patients and Methods: Fifty-three patients with 56 perianal fistulas were included in the current retrospective study. The T2-weighted imaging (T2WI) and DWMRI were performed and apparent diffusion coefficient (ADC) values of fistulas were measured. Fistulas were classified into two groups: only perianal fistulas and fistulas accompanied by abscess. Fistulas were also classified into two groups, based on clinical findings: positive inflammatory activity (PIA) and negative inflammatory activity (NIA).

Results: Mean ADC value $\left(\mathrm{mm}^{2} / \mathrm{s}\right)$ of PIA group was significantly lower than that of NIA group, regarding lesions in patients with abscessassociated fistulas $\left(1.371 \times 10^{-3} \pm 0.168 \times 10^{-3} \mathrm{vs} .1 .586 \times 10^{-3} \pm 0.136 \times 10^{-3} ; \mathrm{P}=0.036\right)$. No statistically significant difference was found in mean ADC values between PIA and NIA groups, in patients with only perianal fistulas $(P=0.507)$. Perianal fistula visibility was greater with combined evaluation of T2WI and DWMRI than with T2WI, for two reviewers $(\mathrm{P}=0.046$ and $\mathrm{P}=0.014)$.

Conclusion: The DWMRI is a useful technique for evaluating activity of fistulas with abscess. Perianal fistula visibility is greater with combined T2WI and DWMRI than T2WI alone.
\end{abstract}

Keywords: Magnetic Resonance Imaging, Diffusion, Perianal Fistula, Inflammation, Abscess

\section{Background}

Incidence rate of perianal fistulas and abscesses is approximately 1 - 2 per 10,000 , with an approximate $2: 1$ male to female ratio. Underlying causes include cryptoglandular infection, Crohn's disease, radiotherapy, and secondary malignancy (1). Magnetic resonance imaging (MRI) is highly accurate for the depiction of both the primary tract of fistula (sensitivity $=100 \%$; specificity $=86 \%$ ) and abscesses (sensitivity $=96 \%$; specificity $=97 \%$ ) in patients with perianal disease (2). In addition to its usefulness in the anatomic investigation of perianal fistulas, MRI can be used to evaluate the activity of fistulas, which is a significant factor for determining the therapeutic strategy $(3,4)$.

Although active fistulas appear hyperintense on T2weighted images (T2WI), in some cases, hyperintensity of fistulas may be related to edema (5). Increased enhancement on T1-weighted images (T1WI), after intravenous administration of gadolinium-based contrast material, is generally considered indicative of active inflammation
$(5,6)$. Studies have proven the effectiveness of dynamic contrast-enhanced MRI for determining the degree of perianal Crohn's disease activity $(7,8)$. Dynamic contrastenhanced MRI was shown to be useful for identifying perianal Crohn's disease patients, who require close screening for disease progression (7). In addition, the slope of enhancement and peak enhancement, on dynamic series, have been reported to be related to disease activity (8).

Diffusion-weighted MRI (DWMRI) has been shown to be useful for differentiating lesions from the surrounding tissue, in patients with cancer or inflammatory diseases $(9,10)$. Recently, DWMRI has been used to evaluate perianal fistulas $(3,11,12)$. In one of these studies, Yoshizako et al. (3) found that the apparent diffusion coefficient (ADC) values were significantly lower in clinically active fistulas. However, Yoshizako et al. (3) did not make a distinction between fistulas with and without abscess. Although Dohan et al. (12) concluded that DWMRI was help-

Copyright (C) 2015, Tehran University of Medical Sciences and Iranian Society of Radiology. This is an open-access article distributed under the terms of the Creative Commons Attribution-NonCommercial 4.0 International License (http://creativecommons.org/licenses/by-nc/4.0/) which permits copy and redistribute the material just in noncommercial usages, provided the original work is properly cited. 
ful in discriminating between a perianal abscess and an inflammatory mass, however, they did not find any correlation between $\mathrm{ADC}$ values of fistula and disease activity.

\section{Objectives}

In the present study, we evaluated whether abscessassociated fistulas affect perianal disease activity, as assessed by DWMRI, and determined the role of DWMRI in perianal fistula detection.

\section{Patients and Methods}

\subsection{Patients}

In this retrospective study, the study group consisted of 53 patients, with 56 fistulas, who underwent MRI for the diagnosis of perianal fistulas and abscesses, between November 2011 and April 2013. The sample size was not determined statistically. There were 39 male and 14 female patients, with a mean age of 37 years, and a range of $18-70$ years. Concomitant diseases included Crohn's disease (13), ulcerative colitis (2), hematological malignancy (5), and rectal cancer (1). Thirty-two patients had no related disease. Fistulas were classified into two groups: only perianal fistula ( $\mathrm{n}=39$ ) and fistula accompanied by an abscess ( $\mathrm{n}=$ 17). General exclusion criteria for MRI (pregnancy, claustrophobia, pacemaker) were applicable, as exclusion criteria. This retrospective study was approved by the institutional review board and informed consent was waived.

\subsection{Magnetic Resonance Imaging}

The MRI was performed using a 1.5T body MRI system (Magnetom Avanto, Siemens, Erlangen, Germany) and a pelvic phased-array coil. We did not carry out catheterization or bowel preparation of the anal canal or fistula. The MRI protocol consisted of a fat-suppressed non-contrastenhanced T1-weighted sequence (repetition time/echo time $[\mathrm{TR} / \mathrm{TE}]=545 / 8 \mathrm{~ms}$; received bandwidth $=22 \mathrm{kHz}$; section thickness $=6 \mathrm{~mm}$; interslice gap $=0.5 \mathrm{~mm}$; matrix size $=320 \times 216$; field of view $[\mathrm{FOV}]=400 \mathrm{~mm} \times 400 \mathrm{~mm}$; scan time $=2$ minutes $)$ and a T2-weighted sequence $(\mathrm{TR} /$ $\mathrm{TE}=3400 / 100 \mathrm{~ms}$; received bandwidth $=20 \mathrm{kHz}$; section thickness $=4 \mathrm{~mm}$; interslice gap $=0.5 \mathrm{~mm}$; matrix size $=$ $320 \times 240 ; \mathrm{FOV}=250 \mathrm{~mm} \times 250 \mathrm{~mm}$; scan time $=2 \mathrm{~min}-$ utes 52 seconds). The DWMRI parameters were as follows: $\mathrm{TR} / \mathrm{TE}=6400 / 101 \mathrm{~ms}$; slice thickness $=5 \mathrm{~mm}$; interslice gap $=0.5 \mathrm{~mm}$; number of slices $=24 ;$ matrix size $=188 \times$ 192 , with reconstruction to $256 \times 256$; FOV $=385 \mathrm{~mm} \times 385$ mm; bandwidth $=173 \mathrm{kHz}$; number of signal averages $=$ 4 ; b-values of 50,400 and $800 \mathrm{~s} / \mathrm{mm}^{2}$. The scan time for DWMRI was 3 minutes 1 second. The axial plane was used for DWMRI. The T2WI were also obtained in the coronal and sagittal planes.

\subsection{Image Interpretation}

Leonardo console (software version 2.0) (Siemens, Er- langen, Germany) was used for post-processing of MRI data sets. The MRI scans were independently evaluated by two board-certified radiologists (both D.C.O. and S.B. had 10 and 8 years of experience, in abdominal radiology, respectively). At the time of the study, each radiologist had more than 3 years of prior experience evaluating perianal diseases via DWMRI. Although the radiologists were aware that each patient had a perianal disease, they were blinded to other radiological findings, clinical histories, and results of surgeries and blood tests.

\subsubsection{Qualitative Analysis}

The MRI review was performed in three reading sessions, with a two-week interval between consecutive sessions, to avoid recall bias. Reviewers were blind to the results of previous reading sessions. A total of 56 fistulas were reviewed by the two radiologists, for inter-observer reliability. In the first session, only T2WI ("Data set 1"), while in the second session, only diffusion-weighted images ("Data set 2") were evaluated. Finally, in the third session, diffusion-weighted images and T2WI were evaluated, together ("Data set 3"). The visibility of fistulas was graded on a three-point scale from 0 to 2, as follows: $0=$ no evident fistula, $1=$ probably fistula, and $2=$ distinct fistula. Scores of 1 and 2 were indicative of fistula presence.

A perianal fistula was defined as an oval or linear shaped structure that is hypo- to isointense on T1WI and iso- to hyperintense on T2WI. The existence of an abscess was diagnosed when there was a loculated perianal collection, with high signal intensity on diffusion-weighted images or T2WI. The fistulas were classified based on a system developed by Parks et al. (13). This system was also used to describe the locations of the abscesses and major extensions of the fistulas.

\subsubsection{Quantitative Analysis}

One of the radiologists, (D.C.O.) reviewed 'Data set 3' and calculated the ADC values of the fistulas, using axial DWMRI (b-value $=50 \mathrm{~s} / \mathrm{mm}^{2}$ ), as a guide. For the ADC measurement, a circular region of interest (ROI) area was placed on the largest suspected area, and the lowest ADC value was recorded. The mean size of ROIs used for ADC measurements was $27.7 \mathrm{~mm}^{2}$ (range, 12.2 - $44.5 \mathrm{~mm}^{2}$ ).

\subsection{Standard of Reference}

The patients did not receive treatment before MRI. The need for surgery, for a fistula, was determined by a colorectal surgeon (O.S.), based on the following symptoms: severe pain or restriction of daily activity, restriction of sexual activity, reddish and inflated skin, discharge of pus, and increased serum C-reactive protein (CRP) levels (> $5 \mathrm{mg} / \mathrm{L}$, which is the cutoff value between normal and elevated CRP levels at our institution). Surgery was performed under general anesthesia. If pus was present during surgery, the fistulas were considered ac- 
tive. Fistulas, which needed surgery, within ten days after MRI, and which were determined to be active during surgery, were classified in the positive inflammation activity (PIA) group. Surgery was deemed unnecessary, with mild pain, no restriction or slight restriction of daily activity, absence of pus and normal serum CRP levels ( $<5 \mathrm{mg} / \mathrm{L})$. Fistulas were classified in the negative inflammation activity (NIA) group if they did not require surgery or if they were not considered active, during surgery. The colorectal surgeon, used MRI solely for localizing the lesions and not for evaluating fistula activity.

\subsection{Statistical Analysis}

Statistical analyses were performed using SPSS software (version 16.0; SPSS Inc., Chicago, IL, USA). The Cohen $\kappa$ (kappa) test (with a 95\% confidence interval(CI)) was used to evaluate inter-rater reliability (14). The KolmogorovSmirnov test was used to examine the normal distribution of data. The ADC values of the two fistula groups were compared using the Student's t-test when parametric test assumptions were met. The correlation between PIA and ADC was evaluated using the Pearson product moment correlation. Difference in sensitivities between the three MRI datasets were assessed by the Fisher's exact test. The numbers of fistulas detected on the three MRI datasets were compared by the McNemar's test. Statistical significance was accepted at a $\mathrm{P}<0.05$.

\section{Results}

A total of 56 fistulas were observed in 53 patients. Three patients had two fistulas. Classification of fistulas, according to Parks et al. classification system (13) and locations of abscesses are reported in Table 1.

\subsection{Quantitative Evaluation}

In the group of fistulas accompanied by abscess, 13 fistu- las were classified into the PIA group, and four fistulas were classified into the NIA group. A statistically significant difference was found in the ADC values, between PIA (mean $\left.=1.371 \times 10^{-3} ; \mathrm{SD}=0.168 \times 10^{-3}\right)$ and NIA (mean $\left.=1.586 \times 10^{-3} ; \mathrm{SD}=0.136 \times 10^{-3}\right)$ lesions, in the fistulas accompanied by an abscess group $(\mathrm{P}=0.036)$ (Table 2 ). The examples of PIA and NIA fistulas, accompanied by an abscess group, are shown in Figures 1 and 2.

In the group of only perianal fistulas, 18 fistulas were classified into the PIA group, while 21 fistulas were classified into the NIA group. No statistically significant difference in the $\mathrm{ADC}$ values was found between PIA (mean $=1.289 \times$ $\left.10^{-3} ; \mathrm{SD}=0.256 \times 10^{-3}\right)$ and NIA $\left(\right.$ mean $=1.238 \times 10^{-3} ; \mathrm{SD}=$ $\left.0.217 \times 10^{-3}\right)$ lesions, in the only perianal fistula group $(\mathrm{P}=$ 0.507 ) (Table 2). The example of NIA fistula, not accompanied by an abscess, is shown in Figure 3.

When we classified all fistulas into PIA and NIA groups, regardless of the presence of an abscess, 31 fistulas were grouped into the PIA group, and 25 fistulas were grouped into the NIA group. Under this classification, no statistically significant difference was noted in the ADC values, between the PIA $\left(\right.$ mean $\left.=1.323 \times 10^{-3} ; \mathrm{SD}=0.224 \times 10^{-3}\right)$ and NIA ( mean $\left.=1.294 \times 10^{-3} ; \mathrm{SD}=0.242 \times 10^{-3}\right)$ groups $(\mathrm{P}=0.636)$.

Of the 56 fistulas, 50 were detected on the T2-weighted sequence, alone with a sensitivity of $89.3 \%$ (95\% CI: $77.4 \%$ 95.6\%). Fifty-four fistulas were detected on DWMRI, with a sensitivity of $96.4 \%$ (95\% CI: 86.7\% - 99.4\%). Fifty-six fistulas were detected on the combined evaluation with T2WI and DWMRI, with a sensitivity of 100\% (95\% CI: $90 \%-100 \%)$. A statistically significant difference was found between the combined evaluation with T2WI and DWMRI and T2WI alone $(\mathrm{P}=0.03)$. The difference between DWMRI alone and T2WI alone was not statistically significant $(\mathrm{P}$ $=0.289$ ) (Table 3$)$.

\begin{tabular}{lcccc}
\hline \multicolumn{2}{l}{ Table 1. Fistula Types, Based on Classification Scheme Proposed by Parks et al. and Locations of Major Abscesses } \\
\hline Fistula Type & Number of Fistulas & & Locations of Abscesses \\
\cline { 3 - 5 } & & Intersphincteric & Ischioanal & Supralevator \\
\hline Intersphincteric & 30 & 10 & 3 & 1 \\
Transsphincteric & 19 & & 1 & 1 \\
Suprasphincteric & 2 & 10 & 1 & 2 \\
\hline Extrasphincteric & 5 & 5 & 5 & \\
Total & 56 & & & \\
\hline
\end{tabular}

Table 2. Mean Apparent Diffusion Coefficient Values of Positive Inflammation Activity and Negative Inflammation Activity of Fistulas Within Groups of only Perianal Fistula and Fistula Accompanied by Abscess ${ }^{\mathrm{a}}$

\begin{tabular}{lccccc}
\hline & \multicolumn{2}{c}{ ADC Values of PIA Fistulas } & \multicolumn{2}{c}{ ADC Values of NIA Fistulas } \\
\cline { 2 - 4 } & Mean \pm SD $\left(\times \mathbf{1 0}^{-3}\right)$ & n & Mean $\pm \mathbf{S D}\left(\times \mathbf{1 0}^{-3}\right)$ & n & 4 \\
\hline Fistulas With Abscess & $1.371 \pm 0.168$ & 13 & $1.586 \pm 0.136$ & 0.036 b & 21 \\
\hline Only Perianal Fistulas & $1.289 \pm 0.256$ & 18 & $1.238 \pm 0.217$ & 0.507 & 4 \\
\hline
\end{tabular}

\footnotetext{
a Abbreviations: ADC, apparent diffusion coefficient; NIA, negative inflammation activity; PIA, positive inflammation activity.

bignificant difference.
} 


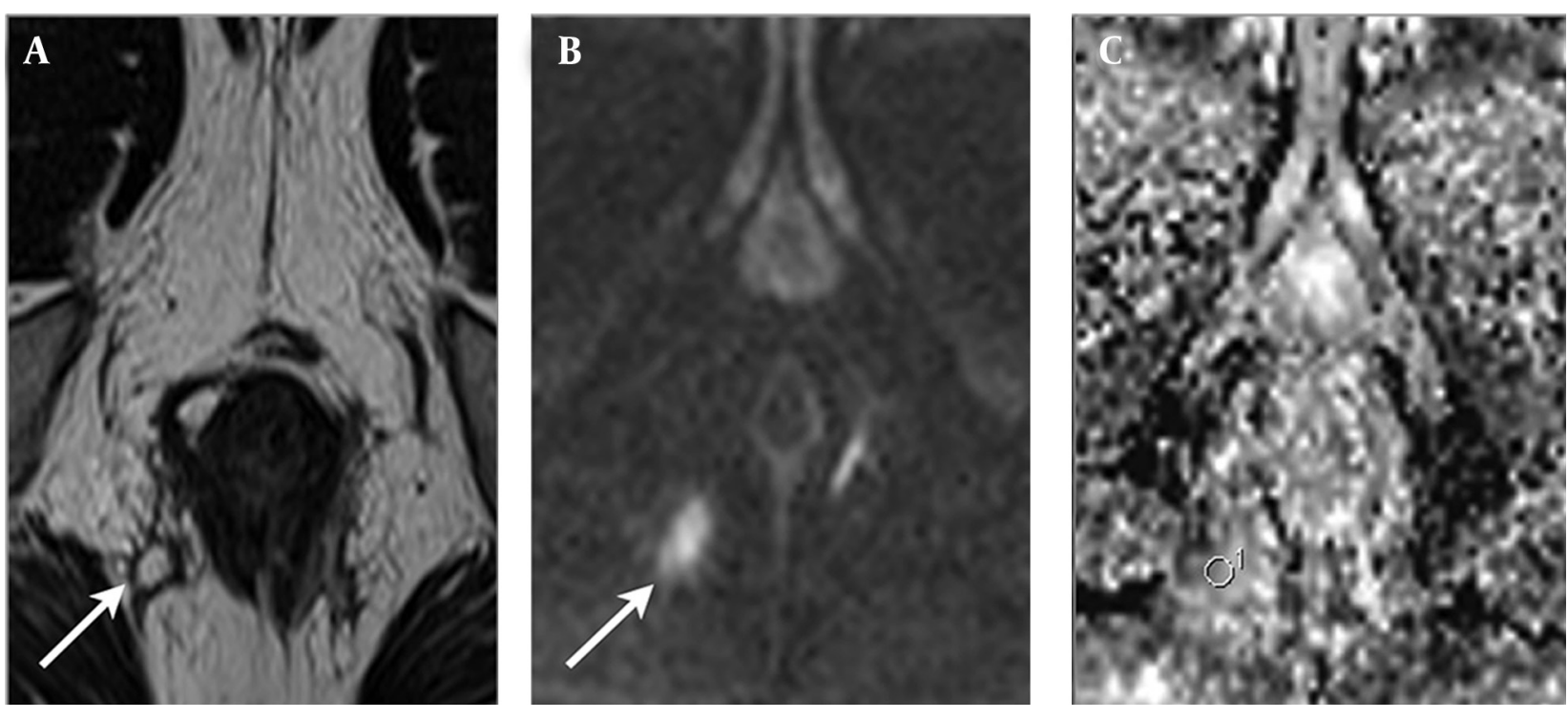

Figure 1. A 30-year-old man with Crohn's disease and transsphincteric positive inflammation activity fistula accompanied by abscess. A, Axial T2-weighted image shows a perianal fistula (arrow) that exhibits high signal intensity. B, Axial diffusion weighted imaging reveals high signal intensity at the fistula (arrow). C, Axial apparent diffusion coefficient mapping shows a value of $1.217 \times 10^{-3}$ for the fistula.
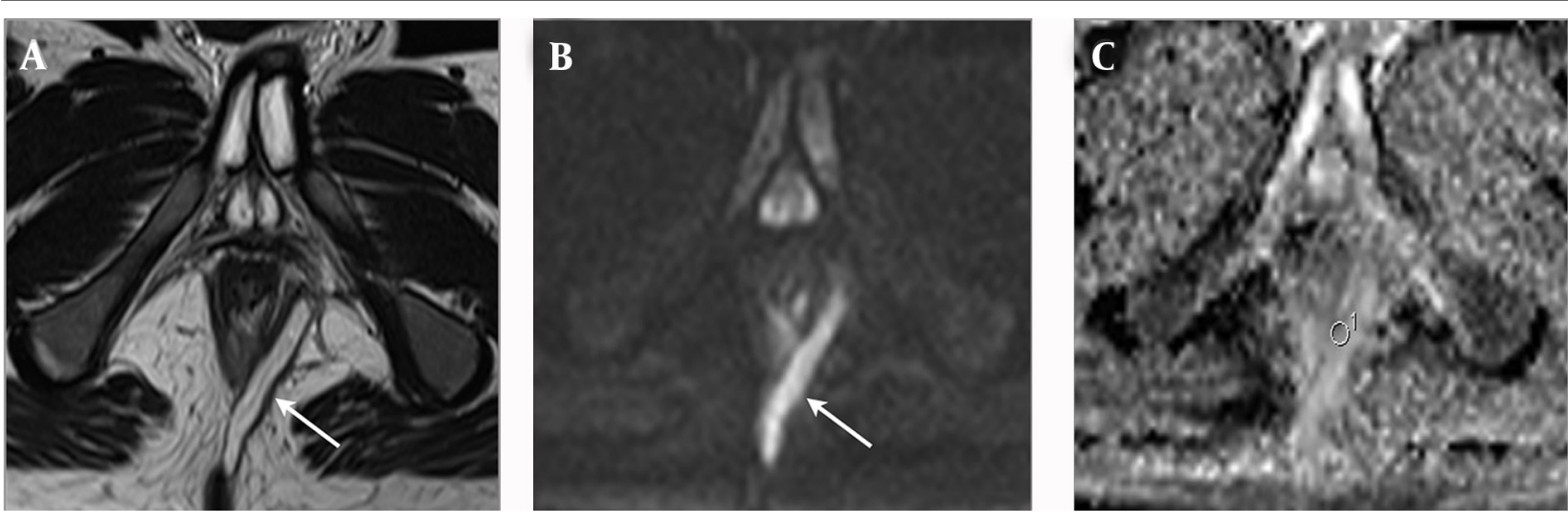

Figure 2. An 18-year-old man with Crohn's disease and transsphincteric negative inflammation activity fistula accompanied by abscess. A, Axial T2-weighted image shows a perianal fistula (arrow) that exhibits high signal intensity. B, Axial diffusion weighted imaging shows high signal intensity at the fistula (arrow). C, Axial apparent diffusion coefficient mapping shows a value of $1.490 \times 10^{-3}$ for the fistula.
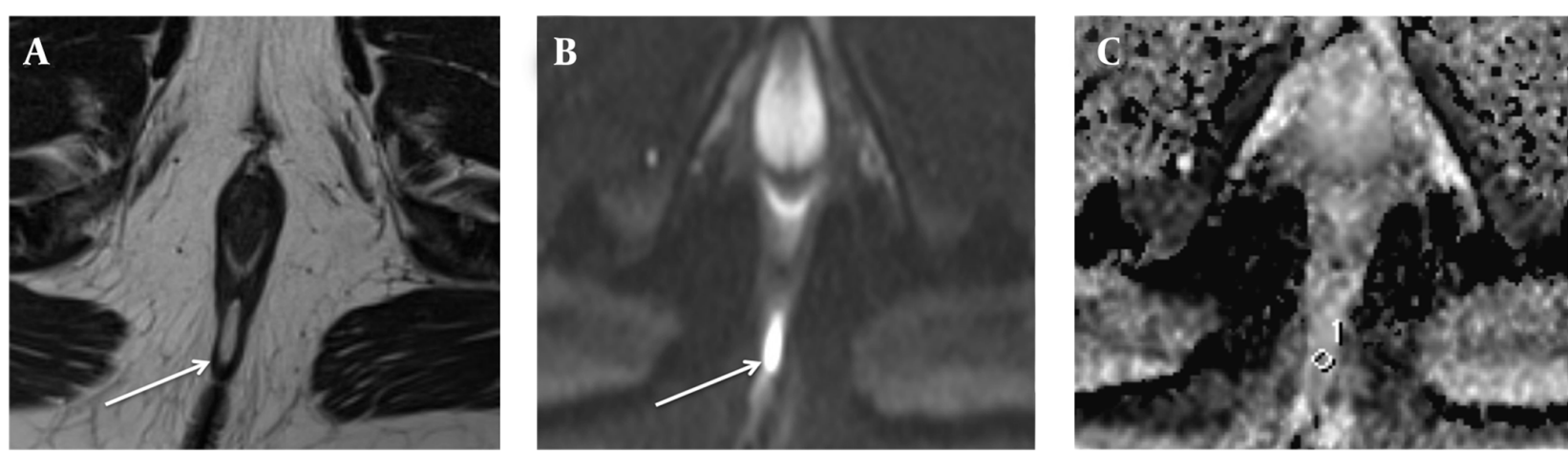

Figure 3. A 28-year-old man (who had no related disease) with an intersphincteric negative inflammation activity fistula not accompanied by abscess. A, Axial T2-weighted image shows a perianal fistula (arrow), exhibiting high signal intensity. B, On axial diffusion weighted imaging, the fistula (arrow) exhibits high signal intensity. C, On the axial apparent diffusion coefficient map, the value of the fistula was $1.301 \times 10^{-3}$. 
Bakan S et al.

\begin{tabular}{|c|c|c|c|}
\hline & T2WI Alone & DWI Alone & T2WI + DWI \\
\hline Number of fistula detected & $50 / 56$ & $54 / 56$ & $56 / 56$ \\
\hline Sensitivity & $89.3 \%(77.4-95.6)^{b}$ & $96.4 \%(86.7-99.4)^{b}$ & $100 \%(90-100)^{\mathrm{C}}$ \\
\hline
\end{tabular}

All of the fistulas $(n=6)$ that were not detected on T2WI were detected on DWMRI. Two fistulas, on the other hand, were detected on T2WI and not on DWMRI. All fistulas were detected on the combined evaluation of T2WI and DWMRI. Agreement between the two independent readers for the number of fistulas was found excellent, on T2WI (kappa = 0.94), and perfect, on DWMRI and on the combined evaluation of T2WI and DWMRI (kappa =1) (14).

\subsection{Qualitative Evaluation}

The visibility of the fistulas was significantly higher on the combined evaluation of T2WI and DWMRI than on T2weighted imaging alone, for both radiologists $(\mathrm{P}=0.046$ and $\mathrm{P}=0.014$, respectively). Agreement between the two radiologists for visibility of fistulas was found good in T2weighted sequence, alone (kappa $=0.77$ ), and perfect in the combined evaluation of T2WI and DWMRI (kappa = 1) (14).

\section{Discussion}

Dynamic-contrast enhanced MRI is often used for the assessment of perianal fistulas and the increased conspicuity of fistula is the most important advantage of this technique (6). Additionally, several studies have shown that dynamic contrast-enhanced MRI can help determine perianal Crohn's disease activity $(7,8)$. However, it has been shown that contrast-enhanced T1WI may exaggerate the degree of perianal disease activity and the number of active fistulas (15). Additionally, clinically inactive fistulas may enhance after intravenous gadolinium administration and may be incorrectly diagnosed as an active fistula (15). Because of the known contraindications of contrast agents that may lead to nephrogenic systemic fibrosis and hypersensitivity (16), alternative MRI methods that provide similar information, as contrast agents, are needed. The DWMRI is an alternative MRI technique that is cost-effective, with a very short imaging time, compared to contrast-enhanced imaging.

Perianal abscesses are quite common in patients with active fistulizing diseases (17). Abscesses are usually manifested by acute onset of pain and require immediate surgical treatment (18). In addition, several symptoms of positive inflammation (i.e., pain at defecation or pain at rest) more frequently occur with perianal abscesses, compared to active and inactive fistulas (19). Previous studies showed that clinical findings and disease activity increase when an abscess accompanies a fistula (17-19). In the present study, the mean ADC value of the PIA fistulas was significantly lower than the mean ADC value of NIA fistulas, in patients with abscess. Conversely, we did not find statistically significant differences between the mean ADC values of the PIA and NIA groups, in patients with only perianal fistulas. Our results indicate that the presence of an abscess causes restricted diffusion and low ADC values in perianal fistulas, which are correlated with fistula activity.

Restricted diffusion has been shown in many different inflammatory processes, including encephalitis, pyelonephritis, and abscesses formation $(20,21)$. In addition, inflammation and fibrosis have been shown to cause decreased ADC values and restricted diffusion in the liver (22). The characteristic histological findings of active Crohn's disease are infiltration of the lamina propria and submucosa of the small bowel, by inflammatory cells, and presence of lymphoid aggregates. Oto et al. (23) reported that these histological findings are characterized by a brighter signal on DWMRI and lower ADC values, in the inflamed bowel wall. In our study, the mean ADC value of the PIA fistulas was found significantly different from the mean ADC value of NIA fistulas, in the presence of an abscess. We suggest that the low ADC values of PIA fistulas, in the present study, could be secondary to increased cellularity, due to perianal inflammation. An increased cell density can narrow the extracellular space and restrict the diffusion of the water molecules in a PIA fistula. Thus, allowing DWMRI discriminating between active and inactive perianal fistulas that are accompanied by an abscess.

Hori et al. (11) and Dohan et al. (12) examined the role of DWMRI in the detection of perianal fistulas. The most important limitation of these studies was their small sample size. Although our study included more fistulas $(n=56)$ than these studies, we did not find any statistically significant difference between the number of fistulas, determined by T2WI alone and by DWMRI alone. In the current study, visibility of fistula tracks was better on the combined evaluation of T2WI and DWMRI, compared to the visibility on T2-weighted alone, which is consistent with the results of Hori et al. (11) and Dohan et al. (12).

In an another study, Yoshizako et al. assessed the value of DWMRI in evaluating perianal fistula activity. Yo- 
Bakan S et al.

shizako et al. (3) found a significant difference in ADCs between PIA and NIA fistulas $(P=0.0019)$ and concluded that DWMRI can be helpful for evaluating perianal fistula activity. Although 30 abscesses were evaluated in their study, Yoshizako et al. (3) did not classify the fistulas based on their association with abscess. In the current study, when we measured ADC values of all fistulas, regardless of the presence of an abscess, we did not find a statistically significant difference between ADC values of PIA and NIA fistulas $(\mathrm{P}=0.636)$.

In a study that examined the role of DWMRI in determining the fistula activity in perianal fistula, Dohan et al. (12) did not find a correlation between ADC values and fistula activity, which is similar to our findings. However, we found a statistically significant correlation between disease activity and ADC values in abscess accompanied fistulas $(P=0.036)$ and suggested that increased fistula activity may be related to the presence of abscesses.

Our study has several limitations. First, a series of subjective clinical findings (pain or restriction of daily or sexual activity) were used, rather than objective surgical, inflammatory, and anatomic parameters. In addition, although the CRP level is the most widely used biochemical marker of inflammation, it is not specific to perianal fistulas and can reflect other inflammatory processes, occurring at the time of the investigation. Second, the visibility of fistulas was evaluated on a 3-point scale, rather than a 5-point scale, which might have affected the findings. Third, the present study was a retrospective and single-center study. Although our sample size for abscess associated fistulas was small, the number of perianal fistulas not accompanied by abscess, evaluated by DWMRI in the current study, is the largest in the published literature. In the future, a prospective study should be performed with a larger number of patients, to clarify the efficacy of DWMRI for determining activity and visibility of perianal fistulas. Finally, in the current study, we did not compare DWMRI with contrast enhanced TiWI and fat-suppressed T2WI, regarding their effectiveness in evaluating disease activity and detecting fistulas.

In conclusion, we found decreased ADC values and restricted diffusion in perianal fistulas, accompanied by abscesses, which show disease activity. Also, in our study, the visibility of fistula tracks was better when DWMRI and T2WI were combined, compared to T2WI alone. Therefore, we concluded that DWMRI is a valuable tool for evaluating fistula activity in patients with perianal abscess and provides better visibility of fistulas compared to T2WI.

\section{Footnotes}

Authors' Contributions: Selim Bakan: data analysis, conception and design, guarantor of study, revised manuscript; deniz Cebi Olgun: data analysis, conception and design; Sedat Giray Kandemirli: draft, data analysis; Onur Tutar: data analysis, data collection; Cesur Samanci: data analysis, data collection; Suleyman Dikici: data analysis, data collection; Osman Simsek: data analysis, data collection; Babak Rafiee: revised manuscript; Ibrahim Adaletli: revised manuscript, data analysis; Ismail Mihmanl: revised manuscript, data analysis.

\section{References}

1. Sainio P. Fistula-in-ano in a defined population. Incidence and epidemiological aspects. Ann Chir Gynaecol. 1984;73(4):219-24. [PubMed: 6508203]

2. Villa C, Pompili G, Franceschelli G, Munari A, Radaelli G, Maconi $\mathrm{G}$, et al. Role of magnetic resonance imaging in evaluation of the activity of perianal Crohn's disease. EurJRadiol.2012;81(4):616-22. doi:10.1016/j.ejrad.2011.01.046. [PubMed: 21316171]

3. Yoshizako T, Wada A, Takahara T, Kwee TC, Nakamura M, Uchida $\mathrm{K}$, et al. Diffusion-weighted MRI for evaluating perianal fistula activity: feasibility study. Eur J Radiol. 2012;81(9):2049-53. doi: 10.1016/j.ejrad.2011.06.052. [PubMed:21767926]

4. Yoshizako T, Kitagaki H. A pictorial review of the impact of adding diffusion-weighted MR imaging to other MR sequences for assessment of anal fistulae. Jpn J Radiol. 2013;31(6):371-6. doi 10.1007/s11604-013-0204-x. [PubMed: 23588593]

5. Halligan S, Stoker J. Imaging of fistula in ano. Radiology. 2006;239(1):18-33. doi: 10.1148/radiol.2391041043. [PubMed: 16567481]

6. Spencer JA, Ward J, Beckingham IJ, Adams C, Ambrose NS. Dynamic contrast-enhanced MR imaging of perianal fistulas. $A J R$ Am J Roentgenol. 1996;167(3):735-41. doi: 10.2214/ajr.167.3.8751692. [PubMed: 8751692]

7. Horsthuis K, Lavini C, Bipat S, Stokkers PC,Stoker J.Perianal Crohn disease: evaluation of dynamic contrast-enhanced MR imaging as an indicator of disease activity. Radiology. 2009;251(2):380-7. doi:10.1148/radiol.2512072128. [PubMed: 19401571]

8. Ziech ML, Lavini C, Bipat S, Ponsioen CY, Spijkerboer AM, Stokkers PC, et al. Dynamic contrast-enhanced MRI in determining disease activity in perianal fistulizing Crohn disease: a pilot study. AJR Am J Roentgenol. 2013;200(2):W170-7. doi: 10.2214/AJR.11.8276. [PubMed: 23345381]

9. Guo AC, Provenzale JM, Cruz Jr LCH, Petrella JR. Cerebral abscesses: investigation using apparent diffusion coefficient maps. Neuroradiology. 2001;43(5):370-4. doi: 10.1007/s002340000519. [PubMed: 11396740]

10. Chan JH, Tsui EY, Luk SH, Fung AS, Yuen MK, Szeto ML, et al Diffusion-weighted MR imaging of the liver: distinguishing hepatic abscess from cystic or necrotic tumor. Abdom Imaging. 2001;26(2):161-5. [PubMed: 11178693]

11. Hori M, Oto A, Orrin S, Suzuki K, Baron RL. Diffusion-weighted MRI: a new tool for the diagnosis of fistula in ano. J Magn Reson Imaging. 2009;30(5):1021-6. doi: 10.1002/jmri.21934. [PubMed: 19856434]

12. Dohan A, Eveno C, Oprea R, Pautrat K, Place V, Pocard M, et al. Diffusion-weighted MR imaging for the diagnosis of abscess complicating fistula-in-ano: preliminary experience. Eur Radiol. 2014;24(11):2906-15. doi: 10.1007/s00330-014-3302-y. [PubMed: 25038854]

13. Parks AG, Gordon PH, Hardcastle JD. A classification of fistula-inano. Br J Surg. 1976;63(1):1-12. [PubMed: 1267867]

14. Landis J, Koch GG. An Application of Hierarchical Kappa-type Statistics in the Assessment of Majority Agreement among Multiple Observers. Biometrics. 1977;33(2):363. doi: 10.2307/2529786. [PubMed: 884196]

15. Morris J, Spencer JA, Ambrose NS. MR imaging classification of perianal fistulas and its implications for patient management. Radiographics. 2000;20(3):623-35. doi: 10.1148| radiographics.20.3.g00mc15623. [PubMed:10835116]

16. Shellock FG, Spinazzi A. MRI safety update 2008: part 1, MRI contrast agents and nephrogenic systemic fibrosis. AJR Am J Roentgenol. 2008;191(4):1129-39. doi: 10.2214/AJR.08.1038.1. [PubMed: 18806155]

17. Wolff BG, Culp CE, Beart RJ, Ilstrup DM, Ready RL. Anorectal Crohn's disease. A long-term perspective. Dis Colon Rectum. 1985;28(10):709-11. [PubMed: 4053875]

18. Safar B, Sands D. Perianal Crohn's disease. Clin Colon Rectal Surg 
2007;20(4):282-93. doi:10.1055/s-2007-991027. [PubMed:20011424]

19. Makowiec F, Jehle EC, Starlinger M. Clinical course of perianal fistulas in Crohn's disease. Gut. 1995;37(5):696-701. [PubMed: 8549948]

20. Kiroglu Y, Calli C, Yunten N, Kitis O, Kocaman A, Karabulut N, et al. Diffusion-weighted MR imaging of viral encephalitis. Neuroradiology. 2006;48(12):875-80. doi: 10.1007/s00234-006-0143-7. [PubMed:16944118]

21. Verswijvel G, Vandecaveye V, Gelin G, Vandevenne J, Grieten $M$, Horvath M, et al. Diffusion-weighted MR imaging in the evaluation of renal infection: preliminary results. JBR-BTR.
2002;85(2):100-3. [PubMed:12083620

22. Bakan AA, Inci E, Bakan S, Gokturk S, Cimilli T. Utility of diffusion-weighted imaging in the evaluation of liver fibrosis. Eur Radiol. 2011;22(3):682-7. doi: 10.1007/s00330-011-2295-z. [PubMed: 21984447]

23. Oto A, Kayhan A, Williams JT, Fan X, Yun L, Arkani S, et al. Active Crohn's disease in the small bowel: evaluation by diffusion weighted imaging and quantitative dynamic contrast enhanced MR imaging. J Magn Reson Imaging. 2011;33(3):615-24. doi:10.1002/ jmri.22435. [PubMed: 21563245] 